\title{
A hybrid myofunctional appliance for hemifacial hypertrophy - A case report
}

\author{
Y. Amin ${ }^{1,6}$, R. Parameswaran ${ }^{2,6}$, K. Soundararajan Nagachandran ${ }^{3,6}$, \\ M. Ramanathan ${ }^{2,6}$, A. Christabel Rajshekaran ${ }^{4,6}$, D. Vijayalakshm ${ }^{5,6}$ \\ 1 Post Graduate Student \\ 2 Professor \\ 3 Reader \\ 4 Former Senior Lecturer \\ 5 Professor and Head of the Department \\ 6 Meenakshiammal Dental College And Hospital, Alapakkam Main Road, Maduravoyal, Chennai-600095, \\ Tamil Nadu, India
}

\begin{abstract}
Introduction : Hemifacial hypertrophy is one of the rare deformities which occur in the craniofacial region. Children who have such deformities are affected not only functionally but also psychologically by the surrounding peer pressure. Treatment in such patients should be carried out as early as possible because of the growth that in present at young age. Hybrid functional appliance helps in correcting the hard and soft tissue imbalance caused by the deformity. This case report describes the treatment modality for the correction of facial deformity using hybrid appliance. A young boy of age 10yrs presented with hemifacial hypertrophy of the right side of the face with chin deviated towards the opposite side because of the excessive growth on right side. He underwent first phase of treatment for the craniofacial deformity for about 4yrs using a Hybrid Myofunctional Appliance. Results: Arch form and dentoalveolar changes were achieved considerably by using hybrid appliance. Chin deviation showed moderate changes with partial correction of the facial asymmetry at the end of first phase of treatment. Conclusion: Achieving an appreciable balance in the alvelolar remodelling and thereby causing change in skeletal parameters using myofunctional appliance can considerably reduce the facial deformity which will reduce the complexity of orthognathic surgery performed at later age.
\end{abstract}

KEYWORDS

Hemifacial hyperplasia, facial asymmetry, hybrid myofunctional

\section{INTRODUCTION}

Asymmetry is the most unusual and fascinating occurrence in human. One such asymmetry, which is characterized with marked unilateral overdevelopment of soft and hard tissues of the face, is the hemifacial hyperplasia which is a very rare developmental anomaly. Hemifacial hyperplasia was first explained by Meckel ${ }^{4}$ in 1822 and was first published by Kottmeier and Wagner ${ }^{3}$ in 1839.
Rowe $(1962)^{7}$ divided hemihypertrophy into (1) simple, (2) complex and (3) hemifacial hypertrophy. Depending on the involvement of soft tissues, bones and teeth, the author further classified hemifacial hypertrophy into true and partial hemifacial hypertrophy. True hemifacial hypertrophy exhibits unilateral enlargement of all tissues, teeth, bones, and soft tissues, characterized by viscerocranial enlargement, bounded by frontal
Address for correspondence : Dr Yunus Amin, Meenakshiammal Dental College And Hospital, Alapakkam Main Road, Maduravoyal, Chennai-600095, Tamil Nadu, India Email: dryunusamin@yahoo.com
Article received: 27-02-2017

Accepted for publication: 10-03-2017
This is an Open Access article distributed under the terms of the Creative Commons Attribution License (http://creativecommons.org/licenses/by/4.0), which permits unrestricted use, distribution, and reproduction in any medium, provided the original work is properly cited. 


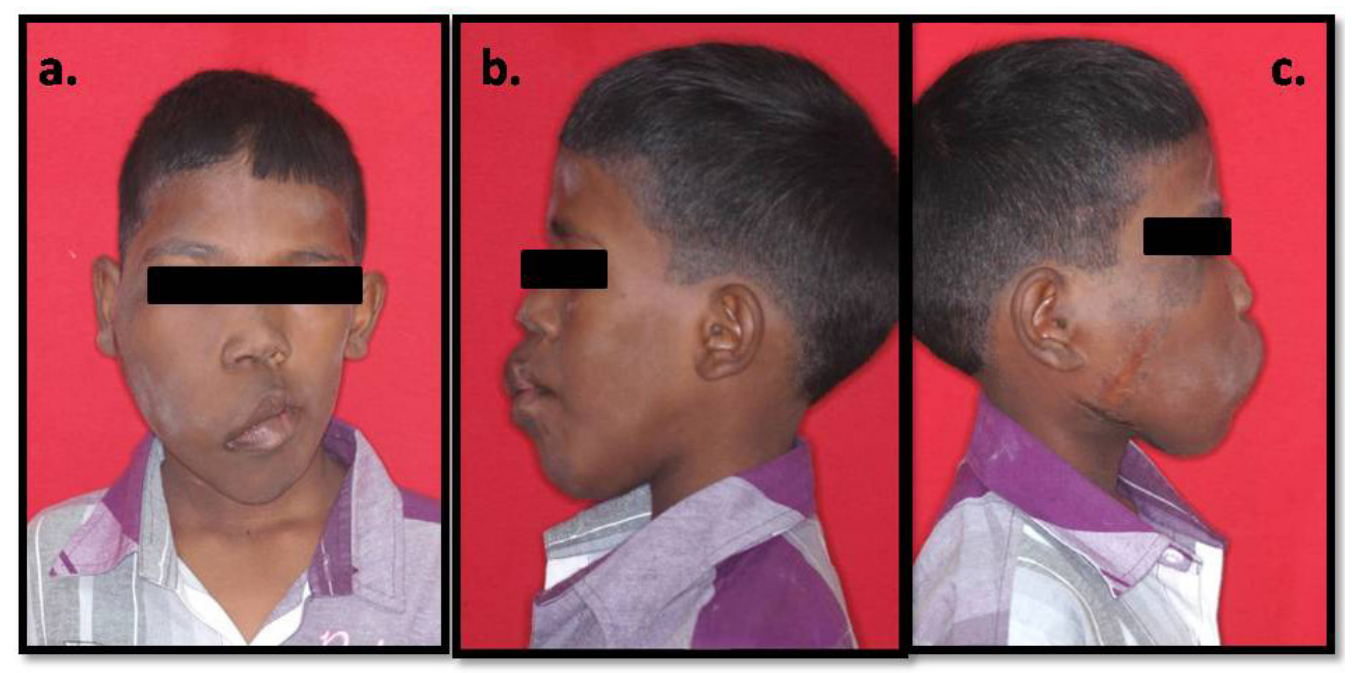

Figure 1

Extra oral photographs (a) Frontal (b) Right profile (c) Left profile

bone superiorly (sparing the eye), inferior border of the mandible inferiorly, midline medially, and ear including the pinna laterally. In partial hemifacial hypertrophy all structures are not enlarged to the same degree neither restricted to one structure. This multisystem involvement has resulted in etiological heterogeneity and no single theory still explains the etiology sufficiently. Factors which can be implicated are heredity, chromosomal abnormalities, atypical forms of twinning, altered intrauterine environment, endocrine dysfunctions, anatomical and functional anomalies of vascular/ lymphatic systems and disturbances of the central nervous system ${ }^{5,2}$.An interesting concept set forth by Gesell (1927) suggests an inequality of regulatory abilities during embryologic development leading to an aberrant twinning mechanism ${ }^{1,2}$. Pollock and co-workers (1985) proffer a hypothesis that the neural tube and its predecessor are unilaterally hyperplastic ${ }^{6}$. The enlarged half of the neural tube which could give rise to proportionally additional abundant neural crest cells on the involved side. The increased number of crest cells persists throughout the prenatal and postnatal growth periods of life and lead to unilateral overgrowth of the crest-derived bone, cartilage, teeth, muscles, and soft tissue. Some tube segments possibly involved more often than others could explain why cephalic areas are more often affected clinically than other areas ${ }^{6}$.

\section{CASE REPORT}

A 10 year old boy was referred to the Department of Orthodontics and Dentofacial Orthopaedics with request for treatment of facial asymmetry which was present from birth. Physical examination revealed a mentally active and a healthy boy. The patient's face was asymmetrical with an enlargement of the right side, including the malar, maxillary, and mandibular region (Fig.1). The pinna of the right ear was also affected and was slightly enlarged and there was deviation of the nose and the chin to the left side. The skin appeared normal with the exception of a small hyper-pigmented patch which was non-hairy on the right cheek region. There was presence of a big scar near the body of the mandible region indicating a debulking procedure that was performed previously. It was understood that the scar enlarged 


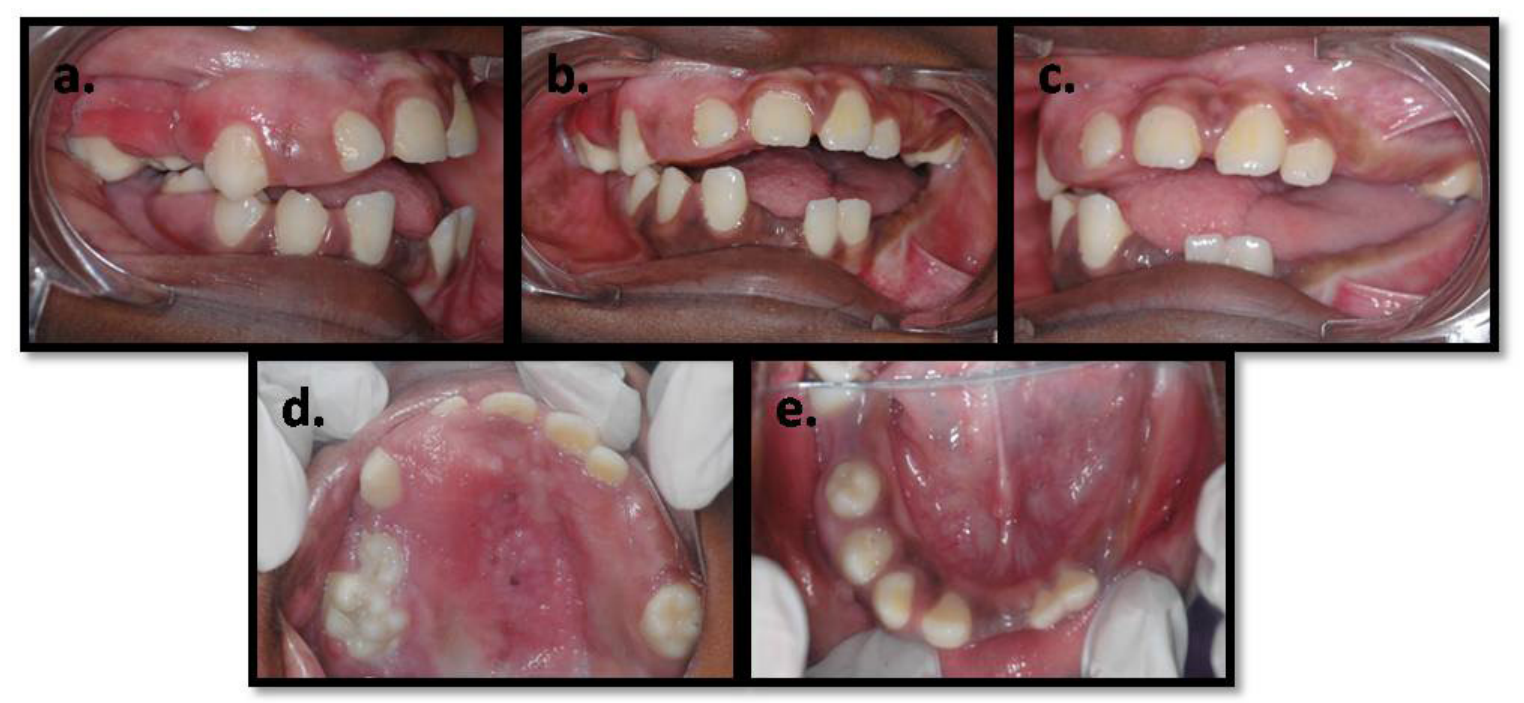

Figure 2

Intra oral photographs (a) Right lateral (b) Frontal (c) Left lateral (d) Upper occlusal (e) Lower occlusal

simultaneously with growth of the patient. There was an enlargement of the tongue also. Speech was not impaired because of the deformity and the sense of taste appeared to be equally distributed.

On intraoral examination a distinct tooth size discrepancy between right and left side was observed (Fig.2). Detailed coronal dimensions of the teeth were measured on the casts using computer software (FACAD VERSION 3.8.0.0) which revealed major variations in size between the teeth of the affected side compared to that of uninvolved side. All the teeth that were present were widely spaced. The right upper first molar was found to be bigger in size when compared with unaffected side. It was found from the previous dental history that the remaining deciduous teeth were subjected to extractions. This might be the reason for the delayed eruption of the remaining permanent teeth. The surface of the gingival tissue and palate on the right side was granular in appearance. Pre treatment OPG showed presence of few missing permanent teeth with enormous enlargement of the right upper and lower alveolar height (Fig.3). There was presence of erupting permanent tooth.
Lateral cephalogram showed a class III skeletal base with prognathic mandible on a high mandibular plane angle. Anteroposterior x-rays were loaded in the digital cephalometric software (FACAD VERSION 3.8.0.0) for frontal and lateral cephalogram analysis. CVMI stage showed second stage indicating that good amount of pubertal growth was present. Anterio-posterior $x$-ray revealed shift of the nasal, maxillary and mandibular base to left side. Biopsy report revealed no malignancy. There was presence of fibro-vascular connective tissue with sheets of non-encapsulated, uniformly arranged mature adipocytes with interdigitating strands of connective tissue. Entrapped and separated atrophic muscle fibres by the adipose tissue are seen. Increased numbers of vessels with thickened muscle walls were also seen.

From the clinical examination and investigations the case was henceforth diagnosed as hemifacial hypertrophy. Since there was growth potential present in the patient, surgical management was strictly ruled out. A conservative approach was then planned for treating the patient and correcting this asymmetry to an extent following the principle of hybrid myofunc- 


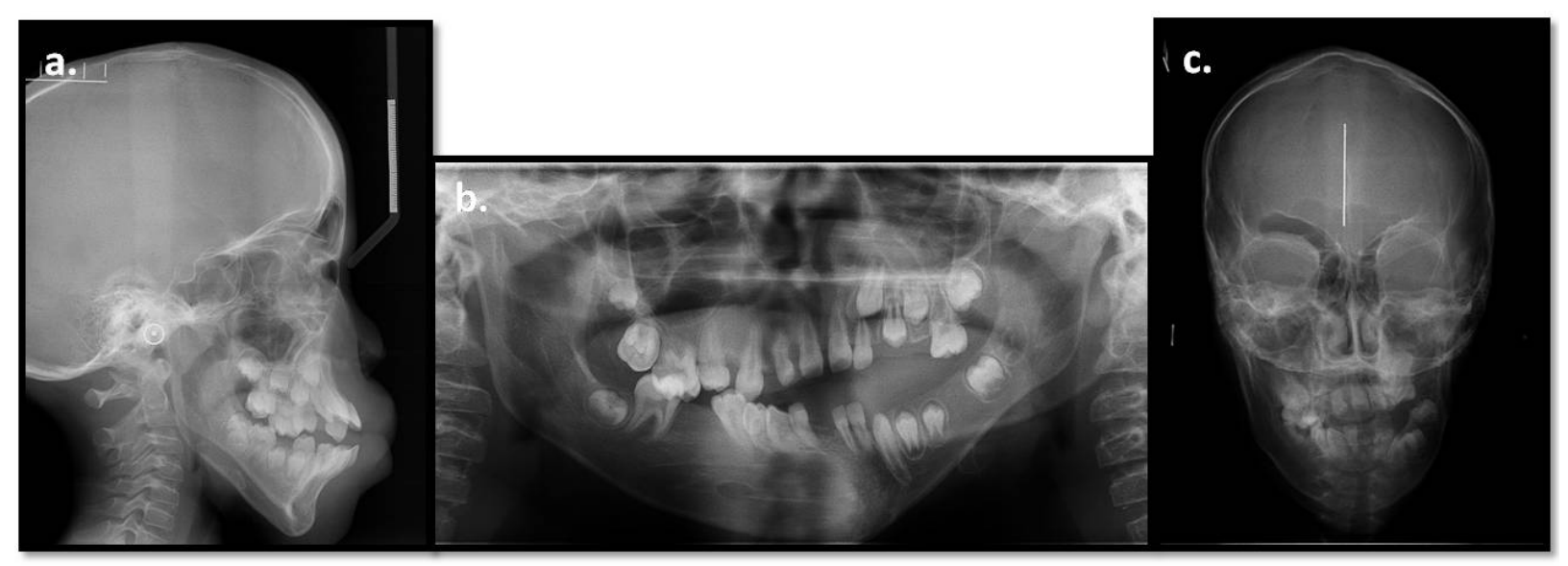

Figure 3

Pre Treatment (a) lateral cephalogram (b) OPG (c) Posteroanterior cephalogram

tional appliance. The principle behind this hybrid appliance was to stop the growth on the affected side as much as possible and to allow growth on the unaffected side leading to partial correction of the asymmetry. Moulding of the dental arches was planned by restricting the tongue forces and allowing good expansion of the lower arch. Right side of the appliance consisted of a bite block which prevented extrusion of the teeth whereas the bite block was trimmed on the left to allow for eruption of the permanent teeth for correction of the canted occlusal plane.

\section{APPLIANCE DESIGN}

The appliance consists of acrylic component and a wire component (Fig.4). Acrylic was extended both on the buccal and lingual side on the right affected side. Buccal shields were not extended more than its vestibular depth. Since the acrylic was both on the buccal and lingual side it restricted the over growth of the affected side. Occlusal surface was loaded with acrylic to prevent over-eruption of the teeth on the affected side. On the unaffected side only lingual acrylic shielding was done allowing free expansion. No acrylic was loaded on the occlusal surface of the unaf- fected side allowing good eruption of the permanent teeth thus by increasing the dentoalveolar height and correcting the canted occlusal plane. A labial bow was placed on the upper arch to prevent sagittal movement of the upper anterior segment and to prevent proclination of the upper anterior teeth.

\section{DISCUSSION}

After the appliance wear good amount of changes were seen both dentally and skeletally. Though the appliance seemed to be little bulky, patient cooperated well to the appliance wear.

The appliance was changed every year because of the growth changes that happened due to the course of the treatment modality. Though lots of restrictions were made on the affected side, moderate growth took place on the affected side whereas good amount of growth occurred in the opposite unaffected side (Fig.5, 6). As compared between pre-treatment and during treatment several changes were observed. Skeletally, the corpus length was increased significantly on the left unaffected side when compared to right affected side which lead to shifting of the menton point towards midline (Fig.7). This 


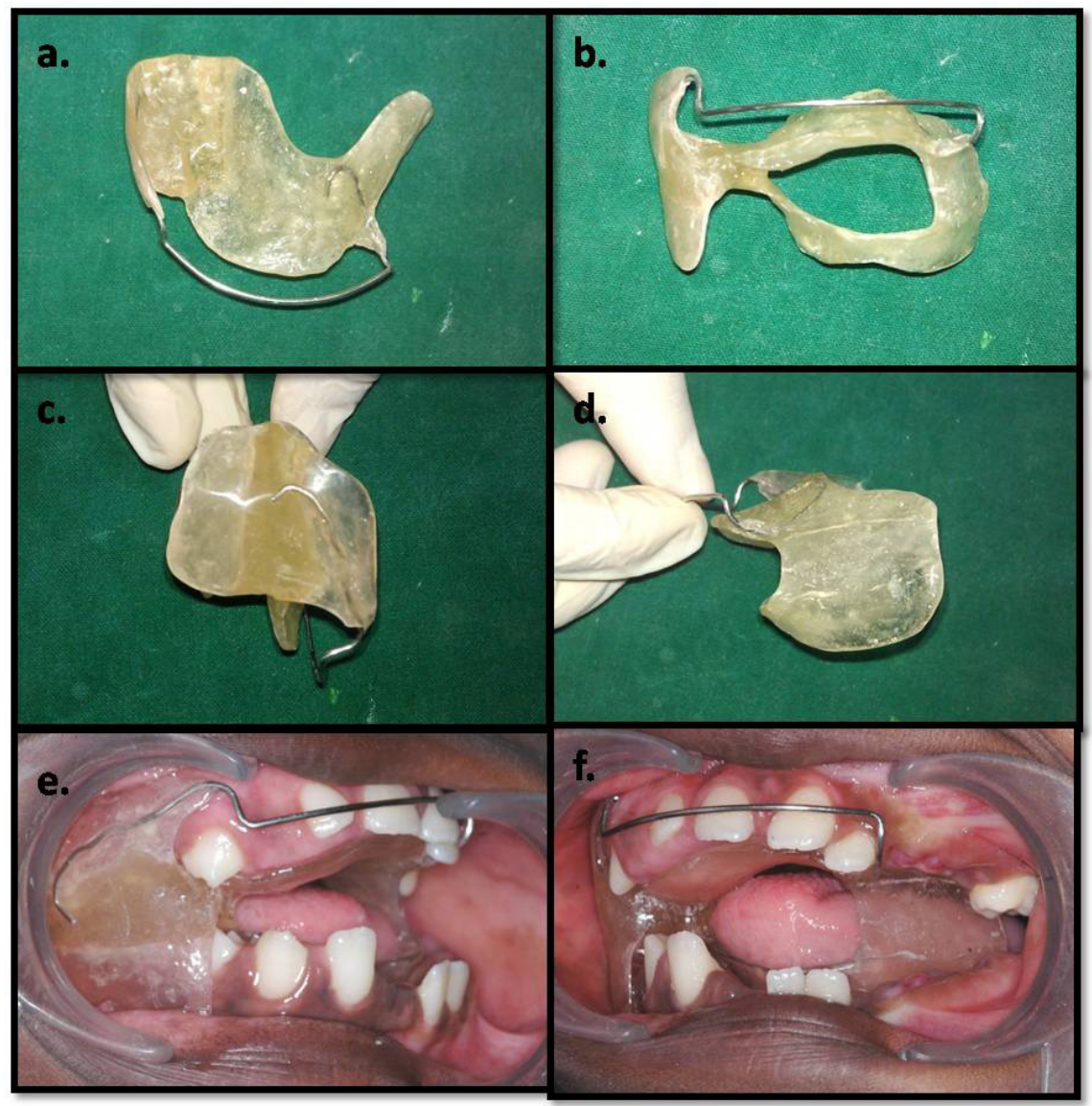

Figure 4

Hybrid Appliance (a) Superior view (b) Frontal view (c) Right lateral view (d) Left lateral view (e) Intra oral right lateral view (f) Intra oral left lateral
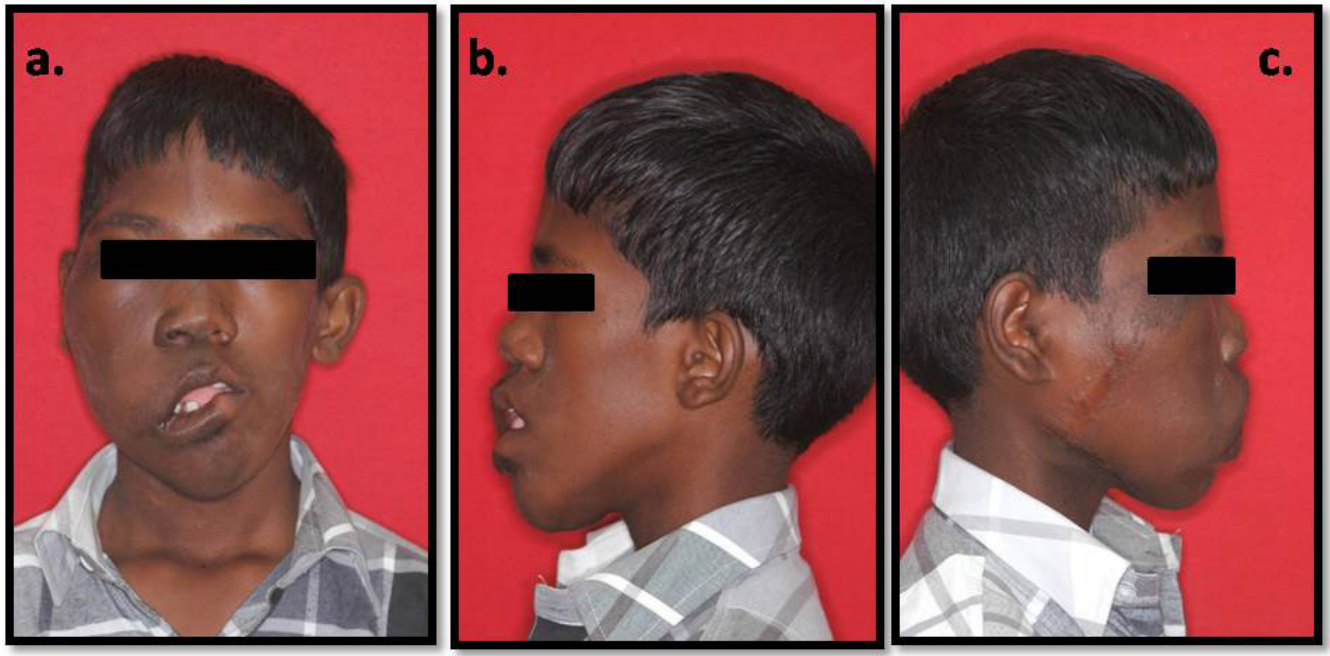

Figure 5

During Treatment (a) Frontal (b) Right profile (c) Left profile 


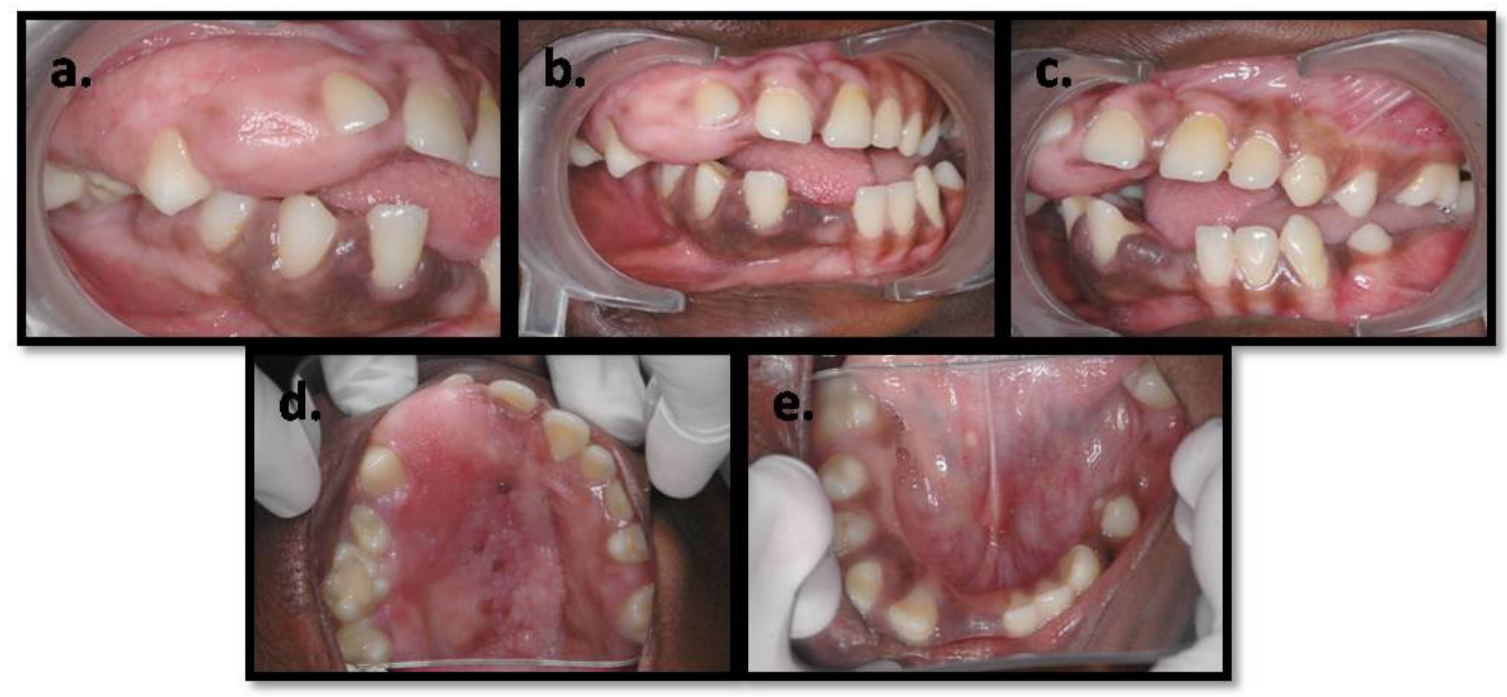

Figure 6

During Treatment Intra oral photographs (a) Right lateral (b) Frontal (c) Left lateral (d) Upper occlusal (e) Lower occlusal

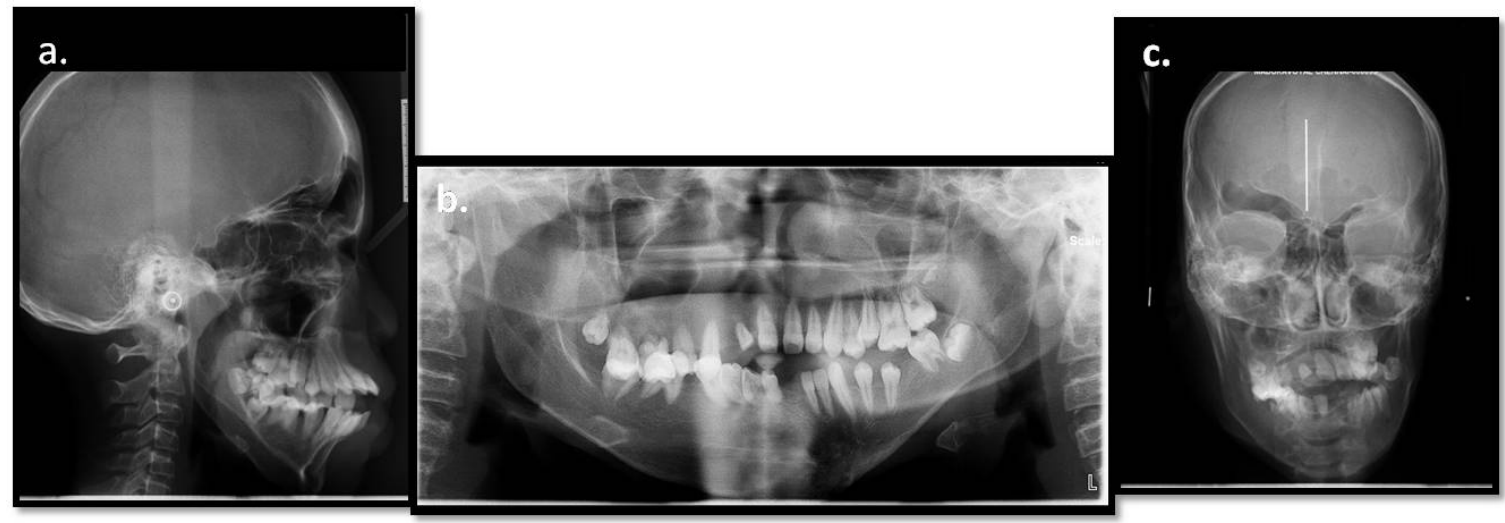

Figure 7

DuringTreatment (a) lateral cephalogram (b) OPG (c) Posteroanterior cephalogram

showed that chin deviation was corrected to an extent. Canting of the upper occlusal plane was corrected by allowing good amount of eruption of permanent teeth on the unaffected (left) side leading to good amount of increase in dentoalveolar height. Mild increase in dentoalveolar height was also observed on the affected (right) side which was comparatively less than the unaffected side. Because of the palatal mucosa being granular in consistency a reference line could not be taken from the mid palatal raphae. Hence a constructed reference plane from the mid- point of the erupted central incisors was drawn and measurements were made from first molar to reference line and canine to reference line measurements were taken. It was found that there was an increase in transverse width on the unaffected (left) side more than the affected (right) side. Deformed arches were moulded to an extent because of the continuous appliance wear (Fig. 8, 9). 


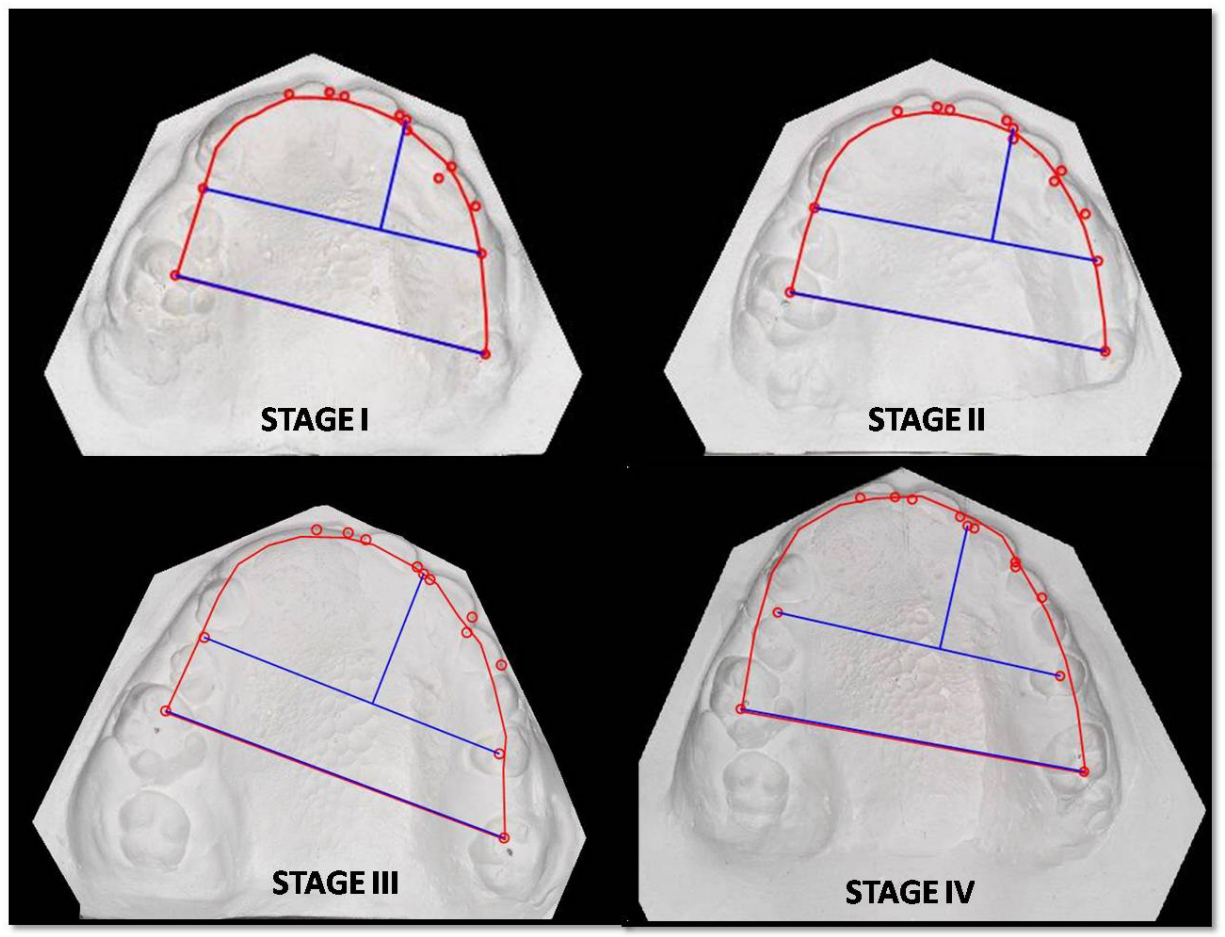

Figure 8

Showing moulding of upper arch in 4 consecutive stages

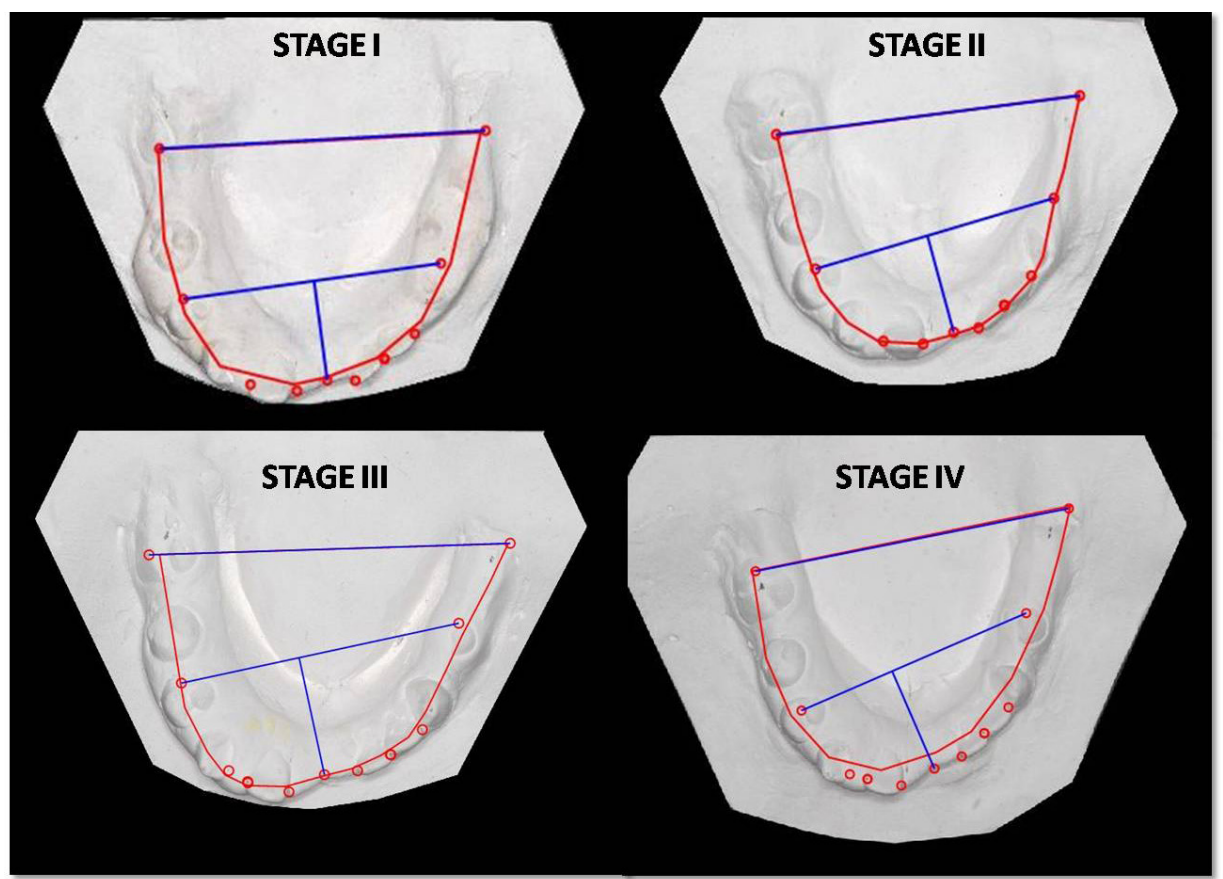

Figure 9

Showing moulding of lower arch in 4 consecutive stages 


\section{CONCLUSION}

Though the hybrid appliance worked satisfactorily on a patient who was affected with hemifacial hypertrophy, patient cooperation is mandatory in such cases. Since the treatment in growing phase requires long term follow-up, the improvements achieved so far was with the span of four years. This case report presented a case of hemifacial hyper- trophy with the initial phase treatment in progress. Later upon growth completion and after final phase of treatment completion the results will be documented.

\section{CONFLICTS OF INTEREST}

the authors have declared that they do not have any conflict of interest

\section{REFERENCES}

1. Gesell A. Hemihypertrophy and twinning. Am J Med Sci 1927 Apr;173(3):542-5.

2. Horswell BB, Holmes AD, Barnett JS et al. Primary hemihypertrophy of the face: Review and report of two cases. Journal of Oral and Maxillofacial Surgery 1987 Mar 1;45(3):217-222.

3. Kottmeier H. Über Hemihypertrophia und Hemiatrophia corporis totalis nebst spontane Extremitätengangräne bei Säuglingen im Anschluss zu einem ungewöhnlichen Fall. Acta Paediatrica 1938 Jun 1;20(4):530-543.

4. Meckel JF. Ueber die seitliche Asymmetric im tierischen Korper. Anatomische Physiologische Beobachtungen und Untersuchungen 1822:147.

5. Nayak R, Baliga MS. Crossed hemifacial hyperplasia: A diagnostic dilemma. Journal of Indian Society of Pedodontics and Preventive Dentistry 2007 Jan 1;25(1):39.

6. Pollock RA, Newman MH, Burdi AR et al. Congenital hemifacial hyperplasia: an embryologic hypothesis and case report. The Cleft palate journal 1985 Jul;22(3):173-184.

7. Rowe NH. Hemifacial hypertrophy: review of the literature and addition of four cases. Oral Surgery, Oral Medicine, Oral Pathology 1962 May 1;15(5):572-587. 